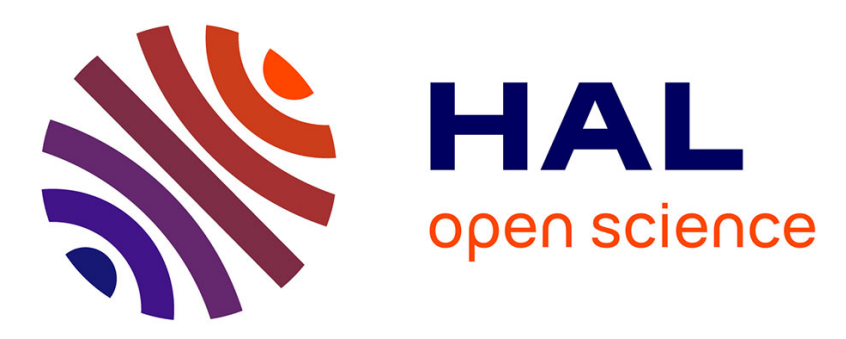

\title{
Identifying Nonresponsive Bleeding Episodes in Patients With Haemophilia and Inhibitors: A Consensus Definition
}

\author{
Erik Berntorp, Peter Collins, Roseline d'Oiron, Nadia Ewing, Alessandro
} Gringeri, Claude Negrier

\section{To cite this version:}

Erik Berntorp, Peter Collins, Roseline d'Oiron, Nadia Ewing, Alessandro Gringeri, et al.. Identifying Nonresponsive Bleeding Episodes in Patients With Haemophilia and Inhibitors: A Consensus Definition. Haemophilia, 2010, 17 (1), 10.1111/j.1365-2516.2010.02377.x . hal-00613809

\section{HAL Id: hal-00613809 https://hal.science/hal-00613809}

Submitted on 6 Aug 2011

HAL is a multi-disciplinary open access archive for the deposit and dissemination of scientific research documents, whether they are published or not. The documents may come from teaching and research institutions in France or abroad, or from public or private research centers.
L'archive ouverte pluridisciplinaire $\mathbf{H A L}$, est destinée au dépôt et à la diffusion de documents scientifiques de niveau recherche, publiés ou non, émanant des établissements d'enseignement et de recherche français ou étrangers, des laboratoires publics ou privés. 


\section{Haemophilia momanamemastion \\ World Federation of Hemophilia}

Identifying Nonresponsive Bleeding Episodes in Patients With Haemophilia and Inhibitors: A Consensus Definition

\begin{tabular}{|r|l|}
\hline Journal: & Haemophilia \\
\hline Manuscript ID: & HAE-00039-2010 \\
\hline Manuscript Type: & Original Article \\
\hline Date Submitted by the & 10 -Feb-2010 \\
\hline Complete List of Authors: & $\begin{array}{l}\text { Berntorp, Erik; Department of Medicine, Department of Coagulation } \\
\text { Disorders } \\
\text { Collins, Peter; Arthur Bloom Haemophilia Centre, University } \\
\text { Hospital of Wales } \\
\text { d'Oiron, Roseline; 3Centre de Traitement pour Hémophiles, AP-HP } \\
\text { Hôpital Bicêtre, Université Paris XI, Hematology } \\
\text { Ewing, Nadia; City of Hope National Medical Center, Division of } \\
\text { Pediatrics } \\
\text { Gringeri, Alessandro; University of Milan, Department of Internal } \\
\text { Medicine } \\
\text { Negrier, Claude; Ctr. Reg. Traitement Hemophille, Hôpital Edouard } \\
\text { Herriot-Pavillon E }\end{array}$ \\
\hline keywords: & $\begin{array}{l}\text { haemophilia, inhibitors, bypassing agents, consensus, treatment, } \\
\text { nonresponsiveness, bleed }\end{array}$ \\
\hline \hline
\end{tabular}


February 10, 2010

Editors: C.A. Lee and C.M. Kessler

Haemophilia

Blackwell Publishing Ltd.

101 George Street

Edinburgh EH2 3ES, UK

\section{Dear Editors:}

I would like to submit the attached manuscript "Identifying Nonresponsive Bleeding Episodes in Patients with Hemophilia and Inhibitors: A Consensus Definition" to Haemophilia for consideration of publication. This manuscript provides a definition for non-life threatening joint and muscle bleeds that are nonresponsive to bypassing agents, and can therefore help guide clinicians to treat patients who have hemophilia and inhibitors with the optimal course of therapy.

This work is an original article and has not been previously published or accepted for any other publication.

I certify that I have no affiliation with or financial involvement in any organization or entity with a direct financial interest in the subject matter or materials discussed in the manuscript.

Thank you for your consideration.

Sincerely,

Erik Berntorp, MD, PhD

Department of Coagulation Disorders

Malmö University Hospital

Malmö, Sweden SE-20502

Phone: 4640332392

Fax: 4640336255

Email: erik.berntorp@med.lu.se 


\title{
Identifying Nonresponsive Bleeding Episodes
}

\section{in Patients With Haemophilia and Inhibitors: A Consensus Definition}

\author{
Erik Berntorp, $\mathrm{MD}, \mathrm{PhD}^{1}$; Peter Collins, $\mathrm{MD}^{2}$; Roseline d'Oiron, $\mathrm{MD}^{3}$; Nadia Ewing, $\mathrm{MD}^{4}$; \\ Alessandro Gringeri, MD, $\mathrm{MSc}^{5}$; Claude Négrier, $\mathrm{MD}, \mathrm{PhD}^{6}$; Guy Young, $\mathrm{MD}^{7}$
}

\author{
${ }^{1}$ Malmö University Hospital, Malmö, Sweden; ${ }^{2}$ University Hospital of Wales, Cardiff, UK; \\ ${ }^{3}$ Centre de Traitement pour Hémophiles, AP-HP Hôpital Bicêtre, Université Paris XI, Le Kremlin- \\ Bicêtre, France; ${ }^{4}$ City of Hope, Duarte, California, USA; ${ }^{5}$ A. Bianchi Bonomi Hemophilia and \\ Thrombosis Center, IRCCS Maggiore Policlinic, Mangiagalli, Regina Elena Hospital Foundation \\ and University of Milan, Milan, Italy; ${ }^{6}$ Centre Régional de Traitement de l'Hémophilie, Lyon, \\ France; ${ }^{7}$ Childrens Hospital Los Angeles, Los Angeles, California, USA
}

\begin{abstract}
Keywords: haemophilia, inhibitors, bypassing agents, consensus, treatment, nonresponsiveness, bleed, pain, swelling, mobility

Running title: Nonresponsive Bleeds in Inhibitor Patients
\end{abstract}

\section{Corresponding Author:}

Erik Berntorp, MD, PhD

Department of Coagulation Disorders

Malmö University Hospital

Malmö, Sweden SE-20502

Phone: 4640332392

Fax: 4640336255

E-mail: erik.berntorp@med.lu.se 


\begin{abstract}
Introduction: Assessing response to treatment with bypassing agents presents a substantial challenge in the treatment of patients with haemophilia and inhibitors. Rapid and accurate identification of bleeding episodes that are nonresponsive to bypassing therapy with either Factor Eight Inhibitor Bypassing Activity (FEIBA; Baxter AG, Vienna, Austria) or recombinant activated factor VII (rFVIIa; NovoSeven ${ }^{\circledR}$, Novo Nordisk A/S, Bagsvaerd, Denmark) is essential to guide treatment decisions and optimise patient outcomes through early intervention. Although both bypassing agents are effective, differential responses to therapy necessitate multiple therapeutic options.
\end{abstract}

Aim: This paper provides a consensus definition for non-life-threatening joint and muscle bleeds that are nonresponsive to bypassing agents.

Methods: An international panel of 7 physicians met in December 2008 to develop the consensus definition using a modified National Institutes of Health Consensus Development Conference method.

Results: The consequent definition of non-life-threatening bleeding episodes that are nonresponsive to bypassing treatment provides a global picture of the condition of the patient during such an event. Identification of nonresponsiveness is based on various criteria: pain, swelling/tension, mobility, patient perception, and laboratory parameters. Criteria can be assessed subjectively by the patient/parent, and/or objectively by the clinician. Although the precise timing of each determination should be at the discretion of the physician, bleeds should be considered nonresponsive if the clinical situation meets the specified criteria 24 hours from the start of treatment.

Conclusion: Although it is not intended to replace clinical judgment, this definition can guide the optimal course of treatment for patients with haemophilia and inhibitors. 


\section{Introduction}

Some patients with haemophilia who are treated with factor replacement therapy develop inhibitory antibodies directed against factor VIII (FVIII) and factor IX (FIX). Development of high titer inhibitors renders conventional factor replacement therapies ineffective; as such, it is the most significant complication of haemophilia therapy [1,2]. Patients with haemophilia are most likely to develop inhibitors in the first 50 days of factor replacement exposure [3]; however, the risk of inhibitor development continues throughout life [4]. Rates of inhibitor development vary according to patient characteristics. Patients with severe haemophilia A develop inhibitors at a rate of 6.4 per 1000 years, whereas those with mild/moderate haemophilia A develop inhibitors at a comparatively decreased rate (1.7 per 1000 years) [5]. Inhibitors develop primarily in patients with haemophilia A, those with severe haemophilia, and children younger than 5 years of age; patients with all of these characteristics experience the highest rate of inhibitor development (34.4 per 1000 years) [5]. Known risk factors for inhibitor development include a family history of inhibitor development, ethnicity, specific FVIII genotypes, and intensive treatment episodes [6, 7]. Proposed risk factors include certain human histocompatibility leukocyte antigen haplotypes [6, 7], polymorphisms in immune response genes [8-10] and FVIII [11], and early age at first exposure to FVIII [6]. There is much debate over whether the use of recombinant or of plasmaderived FVIII is more likely to cause the development of inhibitors [6]; results of recent studies comparing inhibitor incidence in patients previously treated exclusively with one product type or the other do not agree [12-14].

The presence of inhibitors complicates haemophilia treatment and leads to increased morbidity and mortality. Treatment of bleeding episodes can be less effective in inhibitor patients than it is in patients without inhibitors [15] because thrombin generation is not fully reinstated with the use of 
bypassing agents [16]; consequently, greater morbidity is experienced by patients with inhibitors than by patients without inhibitors. Recurrent and uncontrolled joint bleeds lead to orthopedic complications that substantially restrict mobility [17-19], reduce quality of life [18], and can impair work or academic performance [20]. Furthermore, treatment of uncontrolled bleeding episodes can be expensive because patients require prolonged treatment with bypassing agents and analgesics and frequently require hospitalisations [21]. In the past, inhibitor development in patients with haemophilia (human immunodeficiency virus-negative patients) doubled the rate of mortality; however, because of improved treatment options, the presence of inhibitors in patients with severe haemophilia is no longer associated with an elevated mortality rate $[5,15]$. Among patients with mild/moderate haemophilia and inhibitors, the mortality rate has also substantially decreased, although it is still higher than the rate among similar patients who have not developed inhibitors [5].

Early intervention is necessary for optimal patient outcomes. In patients with inhibitors, each bleeding event must be treated in as timely a manner as possible [1]. Swift inhibitor identification facilitates timely initiation of immune tolerance induction therapy or prophylaxis, alterations in dosage or therapy, and detection of family members (especially siblings) who may be at high risk for inhibitors. Rapid, accurate identification of bleeding episodes that are nonresponsive to bypassing agents enables health care providers to make informed treatment decisions at the earliest opportunity. Previously published consensus treatment algorithms, which provide a methodology to guide the treatment of problem bleeds in patients with severe haemophilia A and inhibitors, stress the importance of changing treatment early when inadequate haemostatic response is identified [22]. 
Patients with high-titer inhibitors must be treated with one or both of the currently available bypassing agents: Factor Eight Inhibitor Bypassing Activity, Anti-Inhibitor Coagulant Complex (FEIBA; Baxter AG, Vienna, Austria) and recombinant activated factor VII (rFVIIa; NovoSeven ${ }^{\circledR}$, Novo Nordisk A/S, Bagsvaerd, Denmark). FEIBA is an activated prothrombin complex concentrate (aPCC) composed of numerous coagulation factors; however, activated factor X (FXa) and prothrombin have been shown to be largely responsible for the haemostatic effect of FEIBA [23]. The mechanisms of action of FEIBA target processes in both the extrinsic and intrinsic pathways of coagulation and primarily involve induction of thrombin generation on the platelet surface $[16,23]$. Conversely, rFVIIa affects haemostasis via the extrinsic pathway of coagulation. Recombinant activated factor VII binds weakly to platelets, resulting in a small amount of thrombin generation and activation of factor $\mathrm{X}(\mathrm{FX})$ to $\mathrm{FXa}$, which then increases thrombin production on the surface of platelets [16]. At high doses, rFVIIa binding to platelet surfaces activates enough FX to result in an increase in thrombin to levels that are sufficient to achieve haemostasis [16].

On average, haemostatic responses to FEIBA and rFVIIa are comparable, although overall, reported rates of efficacy vary somewhat [24-27]. With FEIBA, reported rates of efficacy for treatment of all types of bleeding episodes range from approximately $80 \%$ to $100 \%$ [24, 28-30], whereas with rFVIIa, reported efficacy rates range from approximately $60 \%$ to $100 \%$ [31, 32]. For both agents, the highest rates of efficacy were observed during surgical procedures. Although the efficacy percentages reported in these studies vary slightly, in current clinical practice it is assumed that the efficacies of FEIBA and rFVIIa are equivalent. Thrombotic adverse events are rare with the use of either agent $[28,33,34]$, and FEIBA, which is a plasma-derived product manufactured using a vapor heating process, has not been associated with the transmission of pathogens and has a low allergen risk $[35,36]$. Unlike rFVIIa, FEIBA may carry the risk of 
anamnestic response to FVIII or FIX; however, anamnestic responses do not affect the efficacy of FEIBA [24, 26].

A recent head-to-head trial of bypassing agents, the FENOC study [30], assessed the equivalence of FEIBA and rFVIIa. According to the randomised, crossover design, participants received either 1 dose of FEIBA (75-100 IU/kg body weight; target dose, $85 \mathrm{IU} / \mathrm{kg}$ ) administered intravenously, or 2 doses of rFVIIa (90-120 $\mu \mathrm{g} / \mathrm{kg}$ body weight; target dose, $105 \mu \mathrm{g} / \mathrm{kg} \times 2$ ) administered intravenously, with the second dose administered 2 hours after the first dose. Evaluation 6 hours after treatment was the primary study outcome, although evaluations of patient response were also made at 2, 6, 12, 24, 36, and 48 hours. At the 6-hour time point, the efficacy of FEIBA was $80.9 \%$ and the efficacy of rFVIIa was $78.7 \%$. At 12 hours, the efficacy of FEIBA was $80.0 \%$ and the efficacy of rFVIIa was $84.4 \%$. Although the efficacies of FEIBA and rFVIIa were similar at all evaluated time points, the predetermined criterion for equivalence was not met because the confidence interval of the difference in efficacy percentages at 6 hours $(11.4 \%-15.7 \%)$ slightly exceeded the established boundary of $\leq 15 \%$. The statistical criterion for equivalence may not have been met because of a lack of statistical power; this is particularly true for the 6-hour time point $[30,37]$. However, assessments made at early time points were considered more reliable than those performed later because, at early time points, less confounding inflammation existed within the joints [30]. Other potential biases could have occurred because of the nonblinded administration of therapy and the loss of a large portion of the study cohort (almost 20\%) before study completion $[30]$.

A randomised, multicenter, crossover study conducted by Young et al, 2008 [38] evaluated the efficacy and safety of 2 different dosage schedules of rFVIIa $(270 \mu \mathrm{g} / \mathrm{kg} \times 1$ or $90 \mu \mathrm{g} / \mathrm{kg} \times 3$, blinded) and 1 dosage schedule of FEIBA (75 U/kg, open-label) in producing haemostasis in joint 
bleeds in a home-treatment setting. In the group that received rFVIIa $270 \mu \mathrm{g} / \mathrm{kg}, 8.3 \%$ of patients required additional haemostatic agents within 9 hours, whereas $36.4 \%$ of patients in the FEIBA group required additional haemostatics within 9 hours $(p=0.032)$. However, this difference in the requirement for haemostatic agents may have been influenced by the fact that patients in either rFVIIa treatment arm received 3 infusions and, as such, may have been more reluctant to use additional haemostatic agents than patients in the FEIBA treatment arm, who received a single infusion. A subjective global treatment response algorithm used to assess efficacy detected no significant differences in treatment response $(p=0.173)$; however, no validation study was performed to verify that this complicated algorithm measured sufficient diversity in levels of treatment response. Furthermore, measurement of patient response was limited to up to 9 hours; this time frame may not have been long enough to evaluate response to treatment in inhibitor patients.

\footnotetext{
Although both FEIBA and rFVIIa are effective and safe for the treatment of bleeding episodes in patients with inhibitors, some patients respond better to FEIBA, whereas some respond better to rFVIIa. Thus, both agents are required for comprehensive inhibitor management. Interpatient variability refers to patient-specific factors in the response to bypassing therapies that may influence the efficacy of these agents. Characteristics that affect factor binding, such as phospholipids bound to platelet surfaces, variation in numbers of platelets, and the presence of platelets with increased binding capacity [27], are examples of such patient-specific factors. In addition, factors that may modulate bleeding, such as natural anticoagulant factors and inherited prothrombotic factors [27], and clotting factors that may affect haemostasis, such as the level of prothrombin present in a patient or the presence of trace levels of uninhibited FVIII [27], may contribute to interpatient variability in responses to rFVIIa and FEIBA. Intrapatient variability, in
} 
which a single patient responds differently in different clinical situations, has also been reported [27].

Recent studies reflect interpatient and intrapatient variability in the response to bypassing therapy. Watts [39] reported on an 8-year-old boy with haemophilia A and a high-responding inhibitor who had a history of successful treatment with FEIBA since the age of 4 years. After undergoing surgery, this patient became nonresponsive to FEIBA but responded well to rFVIIa. Young et al [40] reported on a patient who responds well to FEIBA at a dosage of $75 \mathrm{U} / \mathrm{kg}$, but poorly to rFVIIa at variable dosages (including dosages $>200 \mu \mathrm{g} / \mathrm{kg}$ ). In the FENOC study, discordant pairs demonstrated variable individual responses between bypassing agents [30]. Twenty-nine patients experienced discordant efficacy, in which 1 product was effective but the other was not, at $\geq 1$ time point, although the number of discordant pairs was highest within the first 12 hours of treatment. Nineteen of these patients reported a better response to FEIBA, and 10 patients reported a superior response to rFVIIa, but the study did not address the reproducibility of these results [30].

However, the mean number of joint bleeds was higher in the discordant pairs group than in the concordant pairs group ( 7.3 vs $3.7, p=0.043$ ) in the year before enrollment, suggesting that discordant responses to both agents could have been affected by a previous history of frequent hemarthroses [30].

As evidenced by discordant pairs data, intrapatient variability, and interpatient variability, neither bypassing agent can predictably achieve haemostasis in all patients or in all bleeds [27]. Each agent has distinct, complex mechanisms of action and pharmacokinetics [16,27], and neither completely normalises thrombin generation [16]. Because differential responses to therapy necessitate more than one therapeutic option, both rFVIIa and FEIBA are essential for the treatment of patients with haemophilia and inhibitors [27]. Furthermore, it is important to identify 
treatment failures promptly in order to change treatment strategies and optimise patient outcomes. This statement provides a consensus-based definition for non-life-threatening bleeding episodes that are nonresponsive to bypassing therapy in patients with haemophilia and inhibitors in order to guide therapy and optimise patient outcomes.

\section{Materials and Methods}

A modified National Institutes of Health Consensus Development Conference method [41] was used. According to this method, a comprehensive literature search of the Medline database was performed, in which search terms (ie, bleed*, change, combination, consensus, criteria, efficacy, fail*, FEIBA [aPCC], FEIBA NovoSeven Comparative [FENOC], guidelines, haemophilia, haemostasis, incidence, inadequate, inhibitor, manage*, measure, mechanism, monitor, NovoSeven [rFVIIa], pathophysiology, prevalence, prognosis, response, sequential, switch, therapy, treat*) were combined with the use of Boolean operators (Appendix). Search results were limited to English language articles published in the past 5 years, and animal studies were excluded. The literature search yielded 350 articles that were then inspected for relevance and grouped according to subject matter. The resultant subject matter groupings were used to create agenda topics (Table 1) and meeting objectives. Fifteen of the articles yielded by the literature search were considered most relevant to the agenda topics and to meeting objectives and were chosen for distribution to panel members before the meeting. The primary meeting objective was to develop a consensus definition for bleeding episodes nonresponsive to bypassing therapy in patients with haemophilia and inhibitors; this definition can be used to guide the optimal course of treatment for patients with haemophilia and inhibitors. Secondary objectives were to examine the epidemiology of inhibitors and the morbidity and mortality associated with them, to present data on the efficacy and safety of bypassing therapies, to discuss assessments used to evaluate changes in bleed status, and to provide clinical perspectives on improvement of joint and muscle bleeds in 
inhibitor patients. In addition, future directions for the development of monitoring tools to evaluate response to treatment in inhibitor patients were discussed.

Erik Berntorp, $\mathrm{MD}, \mathrm{PhD}$, was elected chairman of the consensus group by meeting facilitators, and 1 to 2 moderators were chosen, on the basis of their experience and prominence in the inhibitor field, to lead discussion on each agenda topic. Five of the articles deemed most relevant to each agenda topic (Table 1) were distributed for independent study to small groups of panel members who are regarded as experts in those topics. Each small group of expert panel members discussed their agenda topic in a closed-door session convened before the meeting. The entire panel of 7 physicians then met on December 5, 2008, in San Francisco, California, to discuss all agenda topics and fulfill the meeting objectives.

\section{Results}

Development of the consensus definition

Rather than a strict (or overly rigid) definition, this explication of nonresponsive joint and muscle bleeds in patients with haemophilia and inhibitors comprises various criteria for nonresponsiveness: pain, swelling/tension, mobility, patient perception, and laboratory evaluations. Although each criterion for nonresponsiveness was readily decided upon by the consensus group, the manner in which these criteria should be combined to build the definition of nonresponsiveness was a matter of some debate. It was suggested that a nonresponsive joint bleed could be defined by any 1 of the following 3 conditions: the persistence/worsening of pain, a patient's perception of active bleeding, or both an increase/persistence in swelling and a decrease in mobility. Similarly, it was suggested that a nonresponsive muscle bleed could be defined by any 1 of the following: an increase/persistence in swelling, a patient's perception of active bleeding, or both a decrease in mobility and the persistence/worsening of pain. Laboratory parameters were 
intended to complement either of these judgments. Another suggested definition for nonresponsive joint or muscle bleeds gave equal weight to the persistence/worsening of pain, an increase/persistence in swelling, a decrease in mobility, or a patient's perception of active bleeding. According to this suggested definition, the presence of any 1 of these criteria would strongly indicate nonresponsiveness, the presence of 2 criteria would definitely indicate nonresponsiveness, and laboratory evaluations could be used to further aid judgment. Taking into account these different suggestions and the countless variations in individual clinical situations, it was decided that it is not possible to identify a precise number of criteria that must be present in order to define nonresponsiveness. Rather, it is the overall assessment of the patient that is important.

\section{The consensus definition}

This consensus definition of a nonresponsive bleeding episode is intended to provide a global impression of the condition of the patient during a non-life-threatening bleeding episode that is nonresponsive to bypassing treatment, in order to assist in clinical practice and improve patient outcomes. Identification of a nonresponsive bleeding episode is based on the persistence or worsening of pain, an increase or lack of change in swelling/tension, a decrease or lack of change in mobility relative to a bleed-specific baseline, patient perception of an active bleed, and laboratory parameters (Table 2). Clinical judgment must be used to discern which of these criteria are necessary to determine nonresponsiveness for a particular bleeding episode. The criteria can be evaluated via subjective and/or objective assessments. Subjective assessments, made qualitatively by the patient or parent, are frequently used in clinical practice for the evaluation of patients with inhibitors [30] and serve as the starting point and first step in the identification of nonresponsive bleeding episodes. Objective assessments, such as laboratory parameters and qualitative or quantitative assessments made by the physician, are the final step in assessing lack of response to 
treatment. The combination of subjective with objective assessments is a key strength of this approach. It should be noted that the consensus definition of a nonresponsive joint bleed differs somewhat from the definition of a nonresponsive muscle bleed in terms of the relative importance and usefulness of each criterion (Table 2). In general, the mechanisms by which criteria for nonresponsiveness are met differ between joint and muscle bleeds; these differences affect the clinical situation of nonresponsiveness to various degrees.

Even when bleeding episodes undergo appropriate clinical assessment by experienced practitioners in comprehensive care centers, the precise times at which assessments of nonresponsiveness should be made will vary between individual patients and with individual bleed characteristics. For this reason, the exact timing of each determination should be left to the discretion of the treating physician, although the general timing of assessment must be defined in order to clarify the definition of nonresponsiveness. A non-life- or limb-threatening joint or muscle bleed should be considered nonresponsive to bypassing therapy if the clinical situation meets the specified criteria at 24 hours from the start of treatment. This is considered the maximum period needed to assess a lack of response; 24 hours should be sufficient to identify any nonresponsive bleeding episode. The earliest opportunity to identify a nonresponsive bleed may occur at 6 hours after treatment; any time frame shorter than 6 hours is generally insufficient to assess a lack of response to treatment. The time component of the definition of nonresponsive bleeding episodes will vary on the basis of individual patient characteristics, the type of bleed, and the bypassing agent administered. For instance, nonresponsiveness may be assessed more quickly when the condition of a bleeding episode is worsening rapidly than when it is simply persisting. Furthermore, for many joint bleeds, it may be feasible to assess a lack of response after 12 hours, whereas muscle bleeds may require the full 24-hour period to evaluate lack of response. It is important to note that this definition is intended only for non-life- and limb-threatening bleeds, as the evaluation of life- 
and limb-threatening bleeds (eg, intracerebral haemorrhage) requires an accelerated time frame. Lastly, the time interval of assessment must be long enough to maximise the effects of therapy.

Pain serves as a primary criterion in the evaluation of nonresponsive joint bleeds and a secondary criterion in the evaluation of nonresponsive muscle bleeds, because muscle bleeds must grow larger before pain becomes extreme. The persistence or the worsening of pain at 24 hours with or without the use of analgesics can define a nonresponsive joint bleeding episode. Subjective patient evaluation of pain is common, whether it be via global self-assessment or visual analog scale (VAS) measurement. Visual analog scale measurement is recommended, but not necessary, to determine whether pain persists or worsens. Although interpatient variability in self-assessment of pain raises questions of accuracy with VAS measurements, this technique is adequate to evaluate a straightforward, intrapatient increase in or persistence of pain. Furthermore, 4-, 5-, or 10-point visual scales can be adapted for use in young patients over the age of 4 years by adding images of faces as markers to depict various stages of pain. Changes in the level of pain may also be assessed objectively by physician observation. The persistence of pain is obvious to physicians on patient examination; however, worsening of pain may be difficult to evaluate. Effective analgesia masks pain, making assessment of this criterion much less reliable, and variability in the effects of analgesics complicates assessment of pain as a measure of bleed resolution, particularly in mild and moderate joint bleeds. Spontaneous improvement of pain cannot be evaluated during the pharmacological activity of analgesics. In these cases, the response will be evaluated by means of the other objective signs. Despite this obfuscation, the use of and/or response to analgesics can serve as end points in themselves. Pain requiring the use of analgesics is a purely objective criterion, whereas pain that is nonresponsive to analgesics may be evaluated subjectively or objectively, by the patient/parent or the physician, at least in patients who do not otherwise manifest opioid-seeking behaviors. In addition, an experienced clinician can make some judgment 
of a patient's reduced reliance on analgesia in the acute period. Thus, pharmacological analgesia, dose, and dose interval may be important parameters for evaluating response, although there is always a risk that heavy pain treatment may disguise lack of response. Furthermore, individual differences in the ways in which patients cope with pain may blur the utility of this response rating.

Although swelling and mobility are closely related, these parameters should be evaluated separately in the assessment of nonresponsiveness. The persistence or worsening of swelling or tension at 24 hours is a primary criterion in the evaluation of nonresponsiveness to bypassing therapy. Swelling is an important parameter for assessing lack of response in muscle and joint bleeds. However, worsening of swelling in joints can be difficult to evaluate since a bleeding joint will stop swelling at some point, whereas a bleeding muscle can swell to a comparatively larger size. Swelling can be easier to evaluate in muscle bleeds, and the determinations are more reliable. When feasible, the maximal circumference of a muscle should be measured at repeated intervals. When direct measurement is not possible, the size of the hematoma may be evaluated by ultrasound, computed tomography, or magnetic resonance imaging. Examination of the status of blood circulation, innervations, skin appearance distal to the bleed location, and any evidence of vascular or neurological compression may also be important. Swelling or tension must persist or worsen to constitute nonresponsiveness; however, no specific criteria can be given to describe the extent of swelling that must be present. Changes in swelling and tension in visible muscles can be assessed subjectively by the patient/parent and in a more objective manner by physician inspection, which may reveal persistence or increase in the size of the affected area.

With prior knowledge of a patient's arthropathy, judgment of mobility is an important part of the assessment for nonresponsive joint bleeds but has less value in the assessment of muscle bleeds. In 
a nonankylosed joint, any decrease, or lack of improvement, in mobility from the perceived bleedspecific baseline range of motion (ROM) level at 24 hours constitutes a criterion for nonresponsiveness. The patient/parent may evaluate mobility subjectively, whereas the physician may measure goniometric changes in ROM. It is important to consider that synovitis, rather than uncontrolled bleeding, may account for some decrease in mobility. The evaluation of ROM depends on assessment at regular check-ups as well as on assessment of more acute changes during a bleed event. This underscores the importance of careful joint evaluation at a comprehensive care center at regular visits. Mobility varies in each patient and is dependent on baseline ROM; therefore, this assessment must be tailored to each patient's circumstances via the measurement of bleed-specific baseline ROM upon the patient's admittance to the hospital. Clinicians should consider immobilisation of joints that are bleeding and be aware that it is possible for a lack of immobilisation to contribute to a poor response to bypassing therapy.

The previous criteria for nonresponsiveness can be evaluated both objectively and subjectively; however, a patient's perception of the active bleed resists objective quantification, and laboratory evaluations are not interpreted subjectively. In the assessment of nonresponsive joint bleeds, a mature patient's report of absence of the sense of a stopped bleed at 24 hours may be as valuable a criterion as the other subjective parameters. A patient's perception that he is still bleeding, even in the absence of persistent pain, swelling, or decreased mobility, may alter the course of treatment, depending on the specific circumstances. Although a patient's perception of an active bleed is frequently correlated with pain, in many clinical situations, a patient's perception should be regarded as authoritative and should guide the clinician in altering the course of treatment. When a patient has, on many occasions, reliably been able to detect when bleeding has stopped, then this information can be regarded as definitive. Consequently, a clinician should always take into account patient perceptions for the evaluation of treatment response; it is wise to follow the thesis 
that the patient "is always right." In the FENOC study, patient determination of whether the bleeding had stopped was considered a useful way to assess efficacy; patients were confident in their assessments [30], and investigators noted a good correlation with the VAS scores [37].

Objective laboratory parameters are of lesser importance than patient perception of bleeding. In the treatment of a seemingly nonresponsive bleeding episode, imaging and laboratory studies should be strongly considered to rule out other potential causes of pain, swelling, or limited mobility that may be unrelated to the bleeding. Imaging techniques, including ultrasound, computed tomography, magnetic resonance imaging, and x-ray, are more sensitive tools for the evaluation of muscle bleeds than for joint bleeds; however, even when used in muscle haemorrhage, they may not adequately capture the time frame of a problem. Haemoglobin levels can indicate bleed status in muscles. Because nonresponsive bleeding episodes may be the result of incorrect diagnoses, it is important to consider and exclude other congenital and acquired haemostatic disorders; arthrocentesis may be used, with caution, to rule out other causes (ie, septic arthritis). Early data have suggested that there may be a role for the thrombin generation assay (TGA) and thromboelastography (TEG) in evaluation of response to bypassing therapy [40, 42]; however, these assays are still undergoing evaluation and, as such, cannot be used to guide patient care decisions outside the research setting. It remains to be proven that these laboratory parameters are predictive of clinical response to bypassing agents.

\section{Future Directions}

Nonresponsiveness to bypassing agents can be difficult to detect. As reflected in this consensus definition, the optimal method of identification, at present, comprises various clinical criteria assessed subjectively and objectively. However, in the future, the assessment of nonresponsiveness may be enhanced by the introduction of an objective monitoring tool capable of precisely 
measuring thrombin generation or clot formation. Although FVIII or FIX assays are suitable for patients whose low-titer inhibitors can be overwhelmed by large doses of FVIII or FIX, an ideal test, measure, or monitoring tool to assess the response of patients receiving inhibitor therapy is not currently available. In fact, the specific characteristics an ideal test should possess have yet to be defined.

Both TGAs and TEG show promise for predicting the response to bypassing agents in patients with inhibitors. Thrombin generation assays measure the kinetics of thrombin generation in plasma after treatment, whereas TEG and rotational thromboelastometry (ROTEG/ROTEM ${ }^{\circledR}$ ) assess clot formation in whole blood over time. It is possible to accurately measure responses to bypassing agents in vitro with both TGAs and TEG, and some clinicians find these to be valuable tools in a research context. However, TGAs and TEG are not widely available, and neither assay has been adequately validated. Furthermore, the appropriate analytic conditions have not been fully elucidated for either assay, and no controlled data from prospective studies exist to confirm the value of these tools. Standardisation can be achieved by distributing the same constellation of many reagents to various laboratories. A TEG system that utilises whole blood may reflect global haemostasis more accurately than the TGA does and may require less laboratory handling of the patient sample. However, because TEG relies on whole blood, it is not always feasible to use a central laboratory. FEIBA administration increases thrombin generation, and TGAs could potentially be used to accurately monitor response to this agent.

In the future, these laboratory assessments may become standard tools in certain clinical situations, particularly in individualised therapy by helping to optimise the dosage of bypassing therapy for a particular patient [43-45]. Although no large-scale trials focusing solely on TGAs or TEG are currently underway, these assays have been used collaterally in other large studies. Further 
research is needed on the use of TGAs and TEG for measuring treatment efficacy. Large patient populations must be studied, and a broad range of responses to treatment should be gauged. Analytic conditions must be strictly controlled, particularly since there may be variability between patients in different clinical situations, as well as variability between the same patients in bleeding and nonbleeding states. (Although it is difficult to study patients in the bleeding state, this may be possible during some surgeries.) It is hoped that a global assay can predict which patients or bleeding episodes will or will not respond to treatment in a prospective study of well-defined bleeding. Additionally, researchers could look at predictors of efficacy for each agent to evaluate the potential discrepancies in the efficacy of prophylaxis between FEIBA and rFVIIa.

\section{Conclusions}

Treatment outcomes of patients with haemophilia and inhibitors must be improved. At present, the difficulty of assessing response to bypassing treatment presents a substantial challenge in the treatment of inhibitor patients. Although both rFVIIa and FEIBA are effective for the treatment of bleeding episodes in patients with haemophilia and inhibitors, neither agent can predictably achieve haemostasis in all bleeds, patients, or clinical situations. Because differential responses to therapy necessitate more than one therapeutic option, both rFVIIa and FEIBA are necessary for comprehensive inhibitor management. Early treatment and timely, accurate identification of nonresponsive bleeding episodes are essential in order to optimise patient outcomes. This consensus definition for non-life-threatening bleeding episodes that are nonresponsive to bypassing therapy is intended to provide a global picture of the condition of the patient during such as event. Although it is not intended to replace clinical judgment, this definition can guide the course of treatment for patients with haemophilia and inhibitors. Furthermore, thoughtful use of this definition may reduce the costs associated with uncontrolled bleeding. 
Identification of nonresponsiveness is based on the following criteria: the persistence or worsening of pain, an increase or lack of change in swelling/tension, a decrease or lack of change in mobility relative to a bleed-specific baseline, patient perception of an active bleed, and laboratory parameters. The criteria can be assessed subjectively by the patient or parent, and/or objectively by the clinician. Clinical judgment must be used to discern which criteria are necessary to determine nonresponsiveness for a particular bleeding episode. Although the precise timing of each determination should be at the discretion of the physician, in general, a joint or muscle bleed that is not life- or limb-threatening should be considered nonresponsive to bypassing therapy if the clinical situation meets the specified criteria at 24 hours from the start of treatment.

\section{Acknowledgements}

The consensus meeting was facilitated by MedLogix Communications, LLC and received commercial support from Baxter Healthcare. Baxter neither facilitated nor participated in the meeting. The authors would like to thank MedLogix Communications for editorial assistance in developing this manuscript. 


\section{References}

1. Berntorp E, Shapiro A, Astermark J, et al. Inhibitor treatment in haemophilias A and B: summary statement for the 2006 international consensus conference. Haemophilia 2006; 12(Suppl 6): 1-7.

2. DiMichele DM. Inhibitor treatment in haemophilias A and B: inhibitor diagnosis. Haemophilia 2006; 12(Suppl 6): 37-41.

3. Wight J, Paisley S. The epidemiology of inhibitors in haemophilia A: a systematic review. Haemophilia 2003; 9: 418-35.

4. Astermark J. Why do inhibitors develop? Principles of and factors influencing the risk for inhibitor development in haemophilia. Haemophilia 2006; 12(Suppl 3): 52-60.

5. Darby SC, Keeling DM, Spooner RJ, et al. The incidence of factor VIII and factor IX inhibitors in the hemophilia population of the UK and their effect on subsequent mortality, 1977-99. J Thromb Haemost 2004; 2: 1047-54.

6. Hay CR. The epidemiology of factor VIII inhibitors. Haemophilia 2006; 12(Suppl 6): 23-8.

7. Hay CR, Ollier W, Pepper L, et al. HLA class II profile: a weak determinant of factor VIII inhibitor development in severe haemophilia A. UKHCDO Inhibitor Working Party. Thromb Haemost 1997; 77: 234-7.

8. Astermark J, Oldenburg J, Carlson J, et al. Polymorphisms in the TNFA gene and the risk of inhibitor development in patients with hemophilia A. Blood 2006; 108: 3739-45.

9. Astermark J, Oldenburg J, Pavlova A, Berntorp E, Lefvert AK. Polymorphisms in the IL10 but not in the IL1beta and IL4 genes are associated with inhibitor development in patients with hemophilia A. Blood 2006; 107: 3167-72.

10. Astermark J, Wang X, Oldenburg J, Berntorp E, Lefvert AK. Polymorphisms in the CTLA-4 gene and inhibitor development in patients with severe hemophilia A. J Thromb Haemost 2007; 5: 2635. 
11. Viel KR, Ameri A, Abshire TC, et al. Inhibitors of factor VIII in black patients with hemophilia. $N$ Engl J Med 2009; 360: 1618-27.

12. Gouw SC, van der Bom JG, Marijke van den Berg H. Treatment-related risk factors of inhibitor development in previously untreated patients with hemophilia A: the CANAL cohort study. Blood 2007; 109: 4648-54.

13. Goudemand J, Rothschild C, Demiguel V, et al. Influence of the type of factor VIII concentrate on the incidence of factor VIII inhibitors in previously untreated patients with severe hemophilia A. Blood 2006; 107: 46-51.

14. Ettingshausen CE, Kreuz W. Recombinant vs. plasma-derived products, especially those with intact VWF, regarding inhibitor development. Haemophilia 2006; 12(Suppl 6): 102-6.

15. Dimichele D, Rivard G, Hay C, Antunes S. Inhibitors in haemophilia: clinical aspects. Haemophilia 2004; 10(Suppl 4): 140-5.

16. Negrier C, Dargaud Y, Bordet JC. Basic aspects of bypassing agents. Haemophilia 2006; 12(Suppl 6): 48-52.

17. Soucie JM, Cianfrini C, Janco RL, et al. Joint range-of-motion limitations among young males with hemophilia: prevalence and risk factors. Blood 2004; 103: 2467-73.

18. Scalone L, Mantovani LG, Mannucci PM, Gringeri A. Quality of life is associated to the orthopaedic status in haemophilic patients with inhibitors. Haemophilia 2006; 12: 154-62.

19. Rodriguez-Merchan EC. Some recent developments regarding arthropathy and inhibitors in haemophilia. Haemophilia 2008; 14: 242-7.

20. Shapiro AD, Donfield SM, Lynn HS, et al. Defining the impact of hemophilia: the Academic Achievement in Children with Hemophilia Study. Pediatrics 2001; 108: E105.

21. Gringeri A, Mantovani LG, Scalone L, Mannucci PM. Cost of care and quality of life for patients with hemophilia complicated by inhibitors: the COCIS Study Group. Blood 2003; 102: 2358-63. 
22. Teitel J, Berntorp E, Collins P, et al. A systematic approach to controlling problem bleeds in patients with severe congenital haemophilia A and high-titre inhibitors. Haemophilia 2007; 13: 256-63.

23. Turecek PL, Varadi K, Gritsch H, Schwarz HP. FEIBA: mode of action. Haemophilia 2004; 10(Suppl 2): 3-9.

24. Negrier C, Goudemand J, Sultan Y, Bertrand M, Rothschild C, Lauroua P. Multicenter retrospective study on the utilization of FEIBA in France in patients with factor VIII and factor IX inhibitors. French FEIBA Study Group. Factor Eight Bypassing Activity. Thromb Haemost 1997; 77: 1113-9.

25. Parameswaran R, Shapiro AD, Gill JC, Kessler CM. Dose effect and efficacy of rFVIIa in the treatment of haemophilia patients with inhibitors: analysis from the Hemophilia and Thrombosis Research Society Registry. Haemophilia 2005; 11: 100-6.

26. Tjonnfjord GE, Holme PA. Factor eight inhibitor bypass activity (FEIBA) in the management of bleeds in hemophilia patients with high-titer inhibitors. Vasc Health Risk Manag 2007; 3: 527-31.

27. Berntorp E. Differential response to bypassing agents complicates treatment in patients with haemophilia and inhibitors. Haemophilia 2009; 15: 3-10.

28. Dimichele D, Negrier C. A retrospective postlicensure survey of FEIBA efficacy and safety. Haemophilia 2006; 12: 352-62.

29. Hilgartner MW, Knatterud GL. The use of factor eight inhibitor by-passing activity (FEIBA immuno) product for treatment of bleeding episodes in hemophiliacs with inhibitors. Blood 1983; 61: $36-40$.

30. Astermark J, Donfield SM, DiMichele DM, et al. A randomized comparison of bypassing agents in hemophilia complicated by an inhibitor: the FEIBA NovoSeven Comparative (FENOC) Study. Blood 2007; 109: 546-51. 
31. Santagostino E, Mancuso ME, Rocino A, Mancuso G, Scaraggi F, Mannucci PM. A prospective randomized trial of high and standard dosages of recombinant factor VIIa for treatment of hemarthroses in hemophiliacs with inhibitors. J Thromb Haemost 2006; 4: 367-71.

32. Lloyd Jones M, Wight J, Paisley S, Knight C. Control of bleeding in patients with haemophilia A with inhibitors: a systematic review. Haemophilia 2003; 9: 464-520.

33. Aledort LM. Comparative thrombotic event incidence after infusion of recombinant factor VIIa versus factor VIII inhibitor bypass activity. J Thromb Haemost 2004; 2: 1700-8.

34. O'Connell KA, Wood JJ, Wise RP, Lozier JN, Braun MM. Thromboembolic adverse events after use of recombinant human coagulation factor VIIa. JAMA 2006; 295: 293-8.

35. Aledort LM. Factor VIII inhibitor bypassing activity (FEIBA) - addressing safety issues. Haemophilia 2008; 14: 39-43.

36. Allen G, Aledort L. Therapeutic decision-making in inhibitor patients. Am J Hematol 2006; 81: $71-2$.

37. Donfield SM, Astermark J, Lail AE, Gilbert SA, Berntorp E. Value added: increasing the power to assess treatment outcome in joint haemorrhages. Haemophilia 2008; 14: 276-80.

38. Young G, Shafer FE, Rojas P, Seremetis S. Single 270 microg kg(-1)-dose rFVIIa vs. standard 90 microg $\mathrm{kg}(-1)$-dose rFVIIa and APCC for home treatment of joint bleeds in haemophilia patients with inhibitors: a randomized comparison. Haemophilia 2008; 14: 287-94.

39. Watts RG. Successful use of recombinant factor VIIa for emergency fasciotomy in a patient with hemophilia A and high-titer inhibitor unresponsive to factor VIII inhibitor bypassing activity. Am J Hematol 2005; 79: 58-60.

40. Young G, Blain R, Nakagawa P, Nugent DJ. Individualization of bypassing agent treatment for haemophilic patients with inhibitors utilizing thromboelastography. Haemophilia 2006; 12: 598604. 
41. Murphy MK, Black NA, Lamping DL, et al. Consensus development methods, and their use in clinical guideline development. Health Technol Assess 1998; 2: i-iv, 1-88.

42. Varadi K, Turecek PL, Schwarz HP. Thrombin generation assay and other universal tests for monitoring haemophilia therapy. Haemophilia 2004; 10(Suppl 2): 17-21.

43. van Veen JJ, Gatt A, Makris M. Thrombin generation testing in routine clinical practice: are we there yet? Br J Haematol 2008; 142: 889-903.

44. Berntorp E, Salvagno GL. Standardization and clinical utility of thrombin-generation assays. Semin Thromb Hemost 2008; 34: 670-82.

45. Dargaud Y, Luddington R, Gray E, et al. Effect of standardization and normalization on imprecision of calibrated automated thrombography: an international multicentre study. $\mathrm{Br} J$ Haematol 2007; 139: 303-9. 
Table 1. Agenda Topics and References Distributed for Small Group Discussions

Inhibitor Burden and Management in Patients With Haemophilia

- Hay CR. The epidemiology of factor VIII inhibitors. Haemophilia 2006; 12(Suppl 6): 23-8.[6]

- Darby SC, Keeling DM, Spooner RJ, et al. The incidence of factor VIII and factor IX inhibitors in the hemophilia population of the UK and their effect on subsequent mortality, 1977-99. J Thromb Haemost 2004; 2: 1047-54.[5]

- DiMichele DM. Inhibitor treatment in haemophilias A and B: inhibitor diagnosis. Haemophilia 2006; 12(Suppl 6): 37-41.[2]

- DiMichele D, Rivard G, Hay C, Antunes S. Inhibitors in haemophilia: clinical aspects. Haemophilia 2004; 10(Suppl 4): 140-5.[15]

- Berntorp E, Shapiro A, Astermark J, et al. Inhibitor treatment in haemophilias A and B: summary statement for the 2006 international consensus conference. Haemophilia 2006; 12(Suppl 6): 1-7.[1]

Efficacy of Bypassing Therapies for the Management of Acute Bleeds in Patients with Haemophilia and Inhibitors

- Astermark J, Donfield SM, DiMichele DM, et al. A randomized comparison of bypassing agents in hemophilia complicated by an inhibitor: the FEIBA NovoSeven Comparative (FENOC) Study. Blood 2007; 109: 546-51.[30]

- Aledort LM. Comparative thrombotic event incidence after infusion of recombinant factor VIIa versus factor VIII inhibitor bypass activity. J Thromb Haemost 2004; 2: 1700-8.[33]

- Berntorp E. Differential response to bypassing agents complicates treatment in patients with haemophilia and inhibitors. Haemophilia 2009; 15: 3-10.[27]

- Négrier C, Dargaud Y, Bordet JC. Basic aspects of bypassing agents. Haemophilia 2006; 12(Suppl 6): $48-52 .[16]$

- Allen G, Aledort L. Therapeutic decision-making in inhibitor patients. Am J Hematol 2006; 81: 712.[36]

Clinical Experiences: Assessment of Improvement in the Status of Joint and Muscle Bleeds

- Young G, Blain R, Nakagawa P, Nugent DJ. Individualization of bypassing agent treatment for haemophilic patients with inhibitors utilizing thromboelastography. Haemophilia 2006; 12: 598 604.[40]

- Donfield SM, Astermark J, Lail AE, Gilbert SA, Berntorp E. Value added: increasing the power to assess treatment outcome in joint haemorrhages. Haemophilia 2008; 14: 276-80.[37]

- Scalone L, Mantovani LG, Mannucci PM, Gringeri A. Quality of life is associated to the orthopaedic status in haemophilic patients with inhibitors. Haemophilia 2006; 12: 154-62.[18]

- Rodriguez-Merchan EC. Some recent developments regarding arthropathy and inhibitors in haemophilia. Haemophilia 2008; 14: 242-7.[19]

- Váradi K, Turecek PL, Schwarz HP. Thrombin generation assay and other universal tests for monitoring haemophilia therapy. Haemophilia 2004; 10(Suppl 2): 17-21.[42] 


\section{MedL_ógix

Identifying Nonresponsive Bleeding Episodes

Baxter Healthcare

08.17.09 • Manuscript Draft 3

Table 2. Consensus Definition: Criteria to Identify Nonresponsive Joint and Muscle Bleeding Episodes in Patients With

Haemophilia and Inhibitors

\begin{tabular}{|c|c|c|c|c|}
\hline Criteria & Subjective Assessments ${ }^{\mathrm{a}}$ & Objective Assessments $^{\mathrm{a}}$ & $\begin{array}{c}\text { Relative } \\
\text { Importance } \\
\text { for Joint } \\
\text { Bleeds } \\
\end{array}$ & $\begin{array}{c}\text { Relative } \\
\text { Importance } \\
\text { for Muscle } \\
\text { Bleeds }\end{array}$ \\
\hline \multicolumn{5}{|l|}{ Pain } \\
\hline & $\begin{array}{l}\text { - Persistence or worsening of } \\
\text { pain (with and without } \\
\text { analgesics), reported by } \\
\text { patient/parent via global } \\
\text { self-assessment or VAS } \\
\text { - Nonresponsiveness to } \\
\text { analgesics, reported by } \\
\text { patient/parent }\end{array}$ & $\begin{array}{l}\text { - Persistence or worsening of pain, } \\
\text { evaluated by physician assessment } \\
\text { - Need for analgesics } \\
\text { - Nonresponsiveness to analgesics, } \\
\text { evaluated by physician assessment }\end{array}$ & $\begin{array}{l}\text { Primary } \\
\text { measure }\end{array}$ & $\begin{array}{l}\text { Secondary } \\
\text { measure }\end{array}$ \\
\hline \multicolumn{5}{|c|}{ Swelling/tension } \\
\hline & $\begin{array}{l}\text { - Increase or persistence in } \\
\text { swelling, reported by } \\
\text { patient/parent }\end{array}$ & $\begin{array}{l}\text { Increase or persistence in swelling } \\
\text { or tension relative to baseline, } \\
\text { evaluated by size measurements or } \\
\text { physician assessment }\end{array}$ & $\begin{array}{l}\text { Secondary } \\
\text { measure }\end{array}$ & $\begin{array}{l}\text { Primary } \\
\text { measure }\end{array}$ \\
\hline \multicolumn{5}{|l|}{ Mobility } \\
\hline & $\begin{array}{l}\text { - Decrease in mobility, } \\
\text { reported by patient/parent }\end{array}$ & $\begin{array}{l}\text { - Decrease in mobility, evaluated by } \\
\text { goniometric ROM measurements } \\
\text { or physician assessment }\end{array}$ & $\begin{array}{l}\text { Secondary } \\
\text { measure }\end{array}$ & $\begin{array}{l}\text { Of lesser } \\
\text { importance }\end{array}$ \\
\hline \multicolumn{5}{|c|}{ Patient perception } \\
\hline & $\begin{array}{l}\text { - Patient report of the sense of } \\
\text { continuance of bleeding }\end{array}$ & $\ldots$ & $\begin{array}{l}\text { Secondary } \\
\text { measure }\end{array}$ & $\begin{array}{c}\text { Of lesser } \\
\text { importance }\end{array}$ \\
\hline \multicolumn{5}{|c|}{$\begin{array}{l}\text { Laboratory } \\
\text { evaluations }\end{array}$} \\
\hline & $\cdots$ & $\begin{array}{l}\text { - Imaging studies (eg, MRI, } \\
\text { ultrasound, x-ray) } \\
\text { - Arthrocentesis } \\
\text { - TGA } \\
\text { - Haemoglobin levels }\end{array}$ & $\begin{array}{l}\text { TGAs can be } \\
\text { used to } \\
\text { confirm the } \\
\text { hemostatic } \\
\text { response to }\end{array}$ & $\begin{array}{l}\text { Hemoglobin } \\
\text { levels and } \\
\text { imaging are } \\
\text { secondary } \\
\text { measures }\end{array}$ \\
\hline
\end{tabular}

MedLogix Communications, LLC

Page 26 


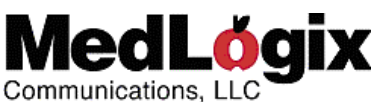

Identifying Nonresponsive Bleeding Episodes

Baxter Healthcare

08.17.09 • Manuscript Draft 3

treatment

Abbreviations: VAS, visual analog scale; ROM, range of motion; MRI, magnetic resonance imaging; TGA, thrombin generation assay.

${ }^{\text {a }}$ Criteria should be assessed at 24 hours from the initiation of treatment. 
08.17.09 • Manuscript Draft 3

\author{
Appendix: Literature Search Strings \\ haemophilia AND inhibitor AND hemostasis \\ haemophilia AND inhibitor AND bleed* AND (manage* OR treat* OR therapy) \\ haemophilia AND inhibitor AND (monitor* OR measure OR criteria) AND (efficacy OR respon*) \\ haemophilia AND inhibitor AND criteria AND (response OR fail*) AND (treatment OR therapy) \\ haemophilia AND inhibitor AND monitor* AND (response OR fail*) AND (treatment OR therapy) \\ haemophilia AND inhibitor AND (treatment OR therapy) AND (respond OR response) \\ haemophilia AND inhibitor AND treat* AND (fail* OR inadequate) \\ haemophilia AND inhibitor AND (treat* OR therapy OR manage*) AND (combination OR sequential) \\ haemophilia AND inhibitor AND combination AND sequential \\ haemophilia AND inhibitor AND (treatment OR therapy) AND (switch OR change OR fail*) \\ haemophilia AND inhibitor AND (treatment OR therapy) AND (switch OR change OR fail*) AND \\ (rFVIIa OR FEIBA OR NovoSeven OR aPCC) \\ FENOC \\ haemophilia AND inhibitor AND FEIBA \\ haemophilia AND inhibitor AND rFVIIa \\ haemophilia AND inhibitor AND prognosis AND (FEIBA OR aPCC OR rFVIIa OR NovoSeven) \\ haemophilia AND inhibitor AND (incidence OR prevalence) \\ haemophilia AND inhibitor AND (pathophysiology OR mechanism) AND (FEIBA OR rFVIIa) \\ haemophilia AND inhibitor AND (consensus OR guideline*) AND (FEIBA or rFVIIa)
}

